\title{
Investigations on mooring system design for a floating platform in shallow water
}

\author{
Hui Liu, Qianqian Jia, Xiaofeng Meng, Haoran Liu, Shuai Guo
}

\begin{abstract}
Based on the finite water depth Green function, Morison equation and coupled dynamic analysis method, dynamic response analysis was performed for a platform in shallow water with different types of mooring systems. The results show that traditional catenary or taut mooring systems, usually adopted for medium or deep water depth, will encounter a range of problems in very shallow water near islands and reefs, and the room for further optimization is very limited. However, the pile anchor chain hybrid mooring system proposed in this paper can overcome these problems, and at the same time, makes ship docking much more convenient. The analysis results in this paper have certain guiding significance for model tests and further design of mooring systems in very shallow water.
\end{abstract}

Index Terms - floating platform; shallow water; mooring system; the pile anchor chain hybrid mooring

\section{INTRODUCTION}

In the periphery of China's marine island reefs, coral reefs with a width of several hundred to several kilometers and shallow water depth are often surrounded. These reefs not only have rich fishery and tourism resources, but also play an important role in eliminating waves and protecting the island. In order to develop marine resources, various floating structures can be deployed near the island reef as a comprehensive support base for marine development, fishery production, environmental tourism, etc. This near-island reef floating platform has the following significant advantages: 1) avoiding a large amount of earthwork Long-distance transport and logistics support of machinery, low cost; 2) almost no impact on the ecological environment, reef and island land form; 3) short on-site construction period, can be quickly deployed; 4) can use China's shipbuilding power Advantages, no difficulty in the design, construction and operation of floating platforms; 5) modular assembly, flexible layout and use.

Hui Liu, School of Naval Architecture \& Ocean Engineering, Jiangsu University of Science and Technology, Zhenjiang, Jiangsu, China

Qianqian Jia, School of Naval Architecture \& Ocean Engineering, Jiangsu University of Science and Technology, Zhenjiang, Jiangsu, China

Xiaofeng Meng, School of Naval Architecture \& Ocean Engineering, Jiangsu University of Science and Technology, Zhenjiang, Jiangsu, China

Haoran Liu Chen, School of Naval Architecture \& Ocean Engineering

, Jiangsu University of Science and Technology, Zhenjiang, Jiangsu, China

Shuai Guo, School of Naval Architecture \& Ocean Engineering , Jiangsu University of Science and Technology, Zhenjiang, Jiangsu, China
For the floating platform near the island reef, it needs to be moored to the working place by the mooring system for a long time. It cannot be avoided like a ship in the case of bad sea conditions, and the floating platform requires the platform to have low-profile motion during production operations. Characteristics, in the survival conditions, the platform is required to be safe and reliable. Therefore, when designing the floating structure, the mooring system is correctly determined to ensure that the parameters of the platform are reasonable in terms of motion response and mooring line tension under operating conditions and survival conditions. The scope is very important.

At present, a lot of researches have been done by domestic and foreign scholars on the hydrodynamic characteristics of floating platforms and their mooring systems. Kim et al $[1,2]$ studied the time domain analysis method of platform mooring system coupling, and analyzed the platform motion response and the dynamic characteristics of the mooring system; Arcandra et al [3] proposed the application of nonlinear rod element method to polyester fiber material. The mooring line is analyzed, considering the large deformation and nonlinear stress-strain characteristics of the mooring line, and the time domain coupling dynamic analysis of the platform system is exemplified. Wang Lei et al [4] carried out a model test on the second-order low-frequency slow drift force of a dynamic positioning ship, and studied the second-order low-frequency slow drift force most concerned in the mooring system; Shi Qiqi, Yuan Meng, Zhou Sulian, Tong Bo, etc. [5-8] The hydrodynamic performance of the deep water semi-submersible platform mooring system was explored by time domain analysis method, and some useful conclusions were obtained. Xiao Longfei et al [9] studied 160kDWT by numerical simulation and model test method. The safety of FPSO movement in extremely shallow water. Based on the three-dimensional potential flow theory and the time-domain coupled dynamic analysis method, this paper takes a near-island semi-submersible production and living platform as the research object, and analyzes the movement and mooring line of the platform under the action of environmental forces under different mooring systems. The tension response provides a reference for the design of the mooring system and the model test of the pool in shallow water environment.

\section{MODEL}

\section{A. Floating platform main parameters}

Taking the production platform of an island reef as the research object, the floating platform is mainly composed of the upper platform, the middle column, the lower pontoon and the cross bracing. The schematic diagram of the platform is shown in Fig. 1. The main parameters are as shown in Table 1. 


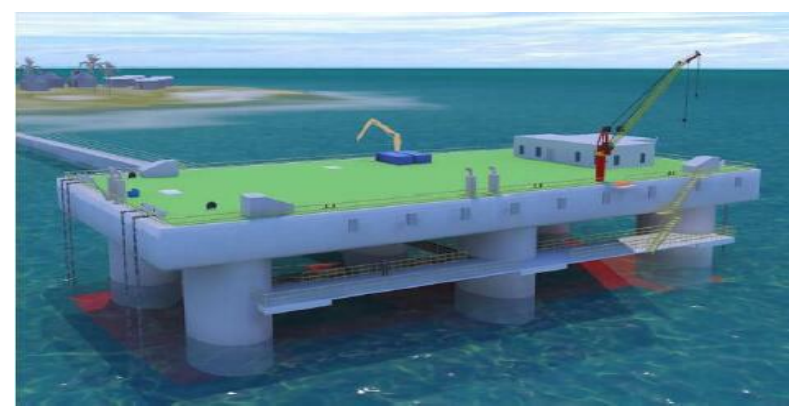

Fig.1. Floating platform in shallow water

Table 1 Main parameters of shallow water floating platform

\begin{tabular}{ccc}
\hline $\begin{array}{c}\text { Platform } \\
\text { parameter }\end{array}$ & Numerical value & Unit \\
\hline Length & 50 & $\mathrm{~m}$ \\
Width & 25 & $\mathrm{~m}$ \\
Height & 13 & $\mathrm{~m}$ \\
Draught (from & 5 & $\mathrm{~m}$ \\
baseline) & & $\mathrm{t}$ \\
Displacement & 2980 & \\
\hline
\end{tabular}

\section{A.Environmental parameters}

The function of the platform is the island reef construction support platform, which integrates the functions of material storage, energy supply and personnel residence. The platform will be mainly arranged inside the reef plate with a water depth of about $20 \mathrm{~m}$ or in the lagoon, according to the existing research data. The environmental conditions under the selected platform's self-storage conditions are shown in Table 2 (due to the arrangement in the lagoon or the inside of the reef, the flow rate of the current is small, and the calculation is not considered at the moment)

Table 2 Environment condition

\begin{tabular}{cccc}
\hline $\boldsymbol{D}(\mathbf{m})$ & $\boldsymbol{H}_{S}(\mathbf{m})$ & $\boldsymbol{T}_{\boldsymbol{P}}(\mathbf{s})$ & $\boldsymbol{V m}(\mathbf{m} / \mathbf{s})$ \\
\hline 20 & 1.25 & 7.5 & 10 \\
\hline
\end{tabular}

\section{B. Calculation method and calibration parameters}

The coupled motion analysis of the platform and the mooring system is carried out in the time domain. The environmental loads on the platform include first-order and second-order wave forces and wind power, wherein the wind contains two parts: average wind and pulsating wind.

Due to the arrangement of the platform near the island reef, it can be proved [10] that when the wave propagates from the deep water area to the shallow water area near the island reef, the direction of the wave will gradually be perpendicular to the shore line. At the same time, generally for floating platforms, the maximum tension will be created on the mooring line when the wind waves are on the same line. Therefore, the calculation in this paper will mainly consider the $90^{\circ}$ direction (the direction of $90^{\circ}$ is the wave and wind propagating along the width of the platform).

Since the function of the platform is positioned as the island reef production and life support platform, the verification parameters in this paper are mainly considered from the functional and safety of the platform, including: motion response (including sway, pitch and roll) and mooring system
( Including mooring line tension, crash pad pressure and mooring pile stress, etc.)。

\section{CATENARY MOORING AND TAUT MOORING}

For floating offshore platforms, catenary mooring and tension mooring are the most common mooring methods. However, these two mooring methods are usually applied in the middle and deep waters. There are no examples of applications in such shallow depths. In this study, the two traditional mooring methods are considered first, and the floating platform suspensions are analyzed separately. The motion response and dynamic response of chain mooring and tension mooring, check the applicability of these two mooring methods in the shallow water environment of the island reef. Figs. 2 and 3 show schematic diagrams of the two mooring modes, and Table 4 gives the main parameters of the two mooring modes.

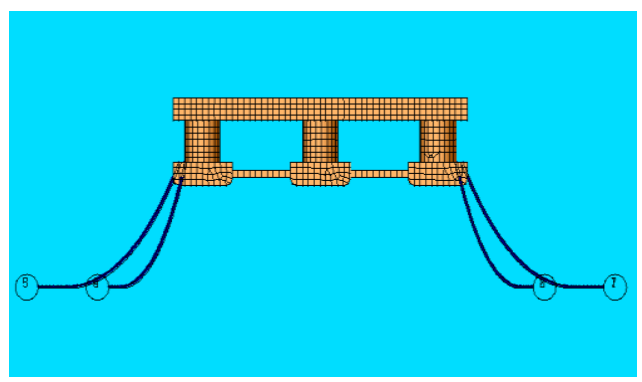

(a)

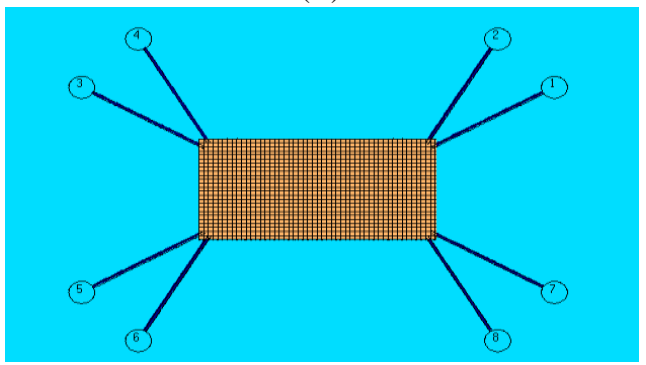

(b)

Fig.2. Catenary mooring

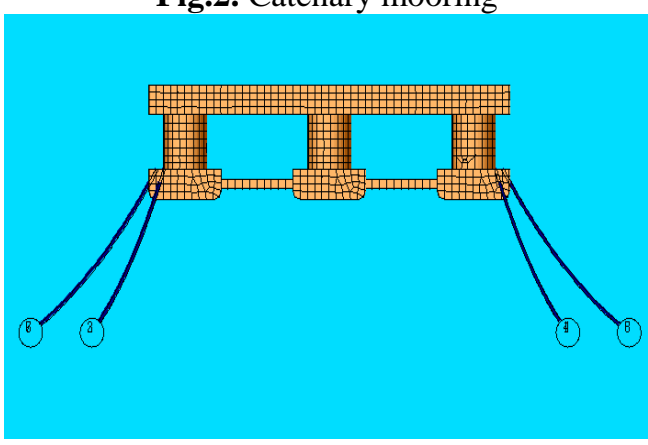

(a)

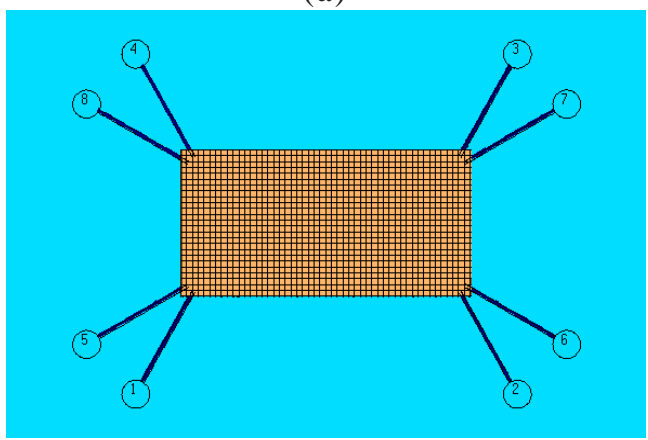

(b)

Fig.3. Taut mooring 
Table.4 Main parameters of mooring lines

\begin{tabular}{|c|c|c|}
\hline & Catenary mooring & Taut mooring \\
\hline Cable formation & Anchor chain & Polyester \\
\hline Length $(\mathrm{m})$ & 38 & 16.9 \\
\hline Diameter $(\mathrm{m})$ & 0.151 & 0.12 \\
\hline $\begin{array}{c}\text { Stiffness } E A \\
(\mathrm{~N})\end{array}$ & $1.70 \mathrm{E} 09$ & $1.58 \mathrm{E} 7$ \\
\hline $\begin{array}{c}\text { Dry weight } \\
(\mathrm{kg} / \mathrm{m})\end{array}$ & 391.6 & 11.5 \\
\hline $\begin{array}{c}\text { Mooring radius } \\
(\mathrm{m})\end{array}$ & $1.57 \mathrm{E} 07$ & $2.5 \mathrm{E} 6$ \\
\hline $\begin{array}{c}\text { Breaking strength } \\
(\mathrm{N})\end{array}$ & & \\
\hline
\end{tabular}

Figs. 4-9 shows the time-domain coupled dynamic analysis results of the catenary mooring scheme and the tensioned mooring platform and the mooring system under the environmental force of $90^{\circ}$ direction, respectively. The statistical results of the mooring line tension are shown in Table 5. Based on the preliminary calculation results, the two mooring schemes were further optimized, mainly from mooring line length, pre-tension, number of mooring lines and tension angle, but they were not well Solve the problem of large platform movement, and the pull-out force of the anchor is also difficult to eliminate.

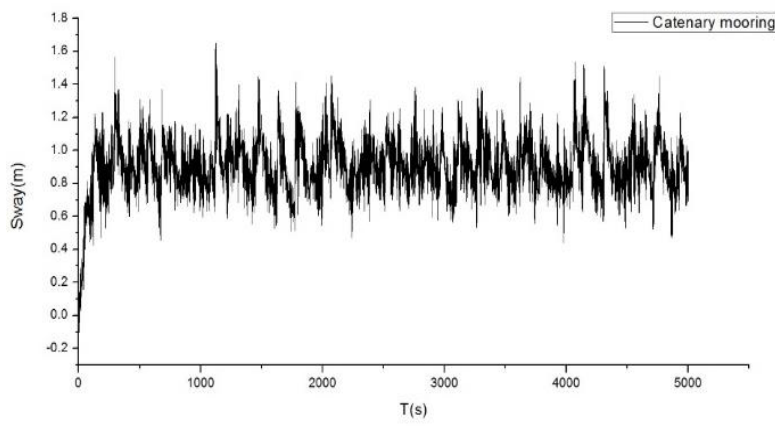

Fig.4. Time history of sway (catenary mooring)

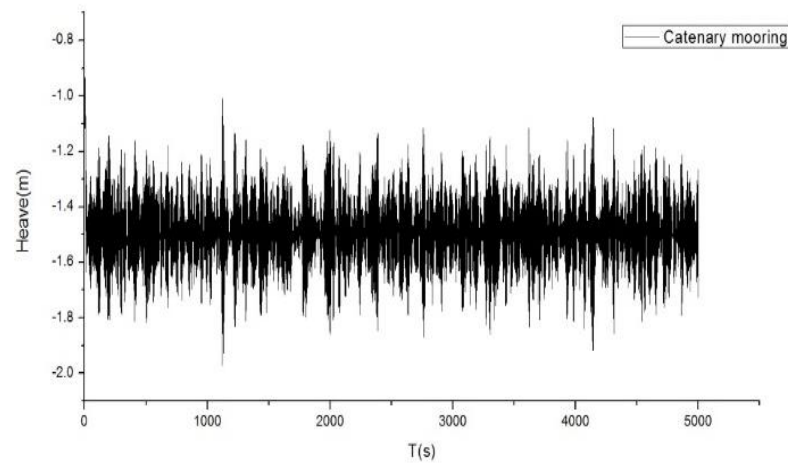

Fig.5. Time history of heave (catenary mooring)

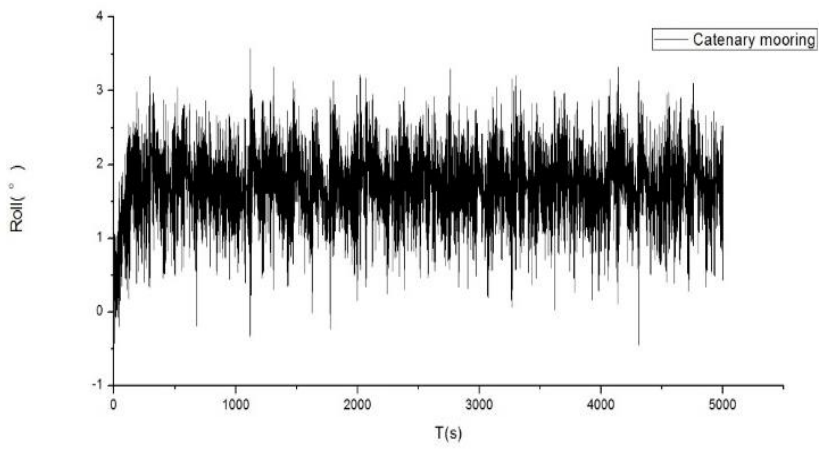

Fig.6. Time history of roll (catenary mooring) Taut mooring

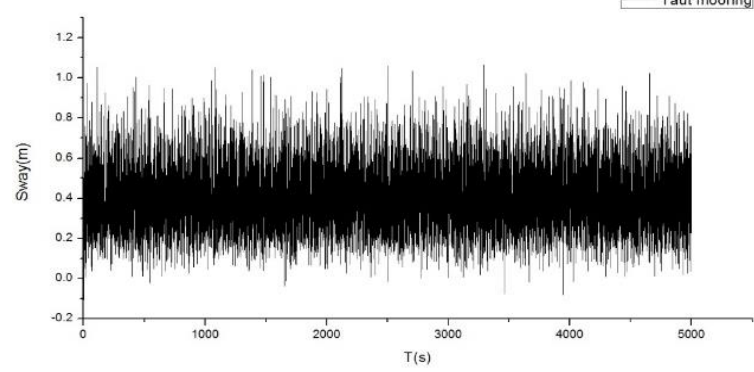

Fig.7. Time history of sway (taut mooring)

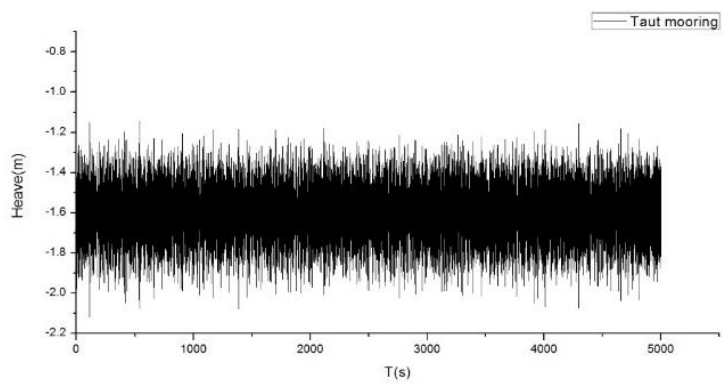

Fig.8. Time history of heave (taut mooring)

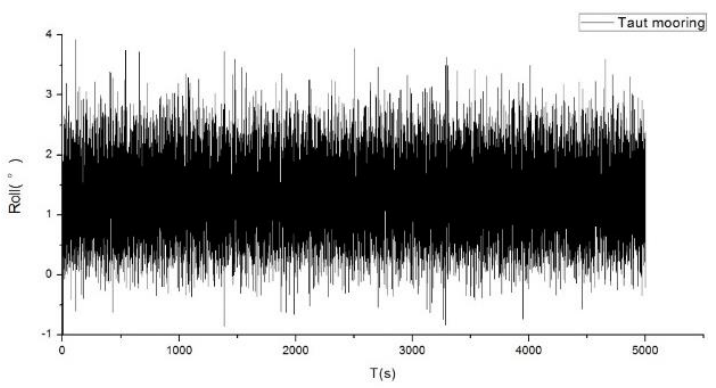

Fig.9. Time history of roll (taut mooring)

Table 5 Tension results of lines

\begin{tabular}{|c|c|c|c|c|}
\hline \multicolumn{2}{|c|}{ Mooring line number } & $\begin{array}{c}\text { Maximum } \\
(\mathrm{kN})\end{array}$ & $\begin{array}{c}\text { Minimum } \\
(\mathrm{kN})\end{array}$ & $\begin{array}{c}\text { Average } \\
(\mathrm{kN})\end{array}$ \\
\hline \multirow{2}{*}{ Mooring line 1} & Catenary & 115 & 101.6 & 109.5 \\
\cline { 2 - 5 } & Taut & 168.5 & 117.6 & 137.2 \\
\hline \multirow{2}{*}{ Mooring line 2 } & Catenary & 110.6 & 93.98 & 104.6 \\
\cline { 2 - 5 } & Taut & 166.5 & 117.6 & 137.2 \\
\hline \multirow{2}{*}{ Mooring line 3 } & Catenary & 115 & 101.7 & 109.7 \\
\cline { 2 - 5 } & Taut & 459.4 & 139.1 & 163.3 \\
\hline \multirow{2}{*}{ Mooring line 4 } & Catenary & 116.2 & 93.8 & 104.6 \\
\cline { 2 - 5 } & Taut & 463 & 139.5 & 163.3 \\
\hline \multirow{2}{*}{ Mooring line 5 } & Catenary & 125.4 & 113.3 & 118.7 \\
\cline { 2 - 5 } & Taut & 179.6 & 131.4 & 147.4 \\
\hline \multirow{2}{*}{ Mooring line 6 } & Catenary & 136.6 & 114.8 & 125.5 \\
\cline { 2 - 5 } & Taut & 180.4 & 131.2 & 147.4 \\
\hline \multirow{2}{*}{ Mooring line 7 } & Catenary & 125.1 & 113.5 & 118.7 \\
\cline { 2 - 5 } & Taut & 283.7 & 132.8 & 149.3 \\
\hline \multirow{2}{*}{ Mooring line 8 } & Catenary & 136.6 & 114.7 & 125.5 \\
\cline { 2 - 5 } & Taut & 291.9 & 133.2 & 149.3 \\
\hline
\end{tabular}

\section{PILE ANCHOR CHAIN HYBRID MOORING}

In addition to the above problems in the catenary and tension mooring schemes, the two mooring methods are also susceptible to the influence and constraints of the seabed topography, and at the same time interfere with the berthing of the ship, requiring an auxiliary berthing device. Based on the above considerations, a new type of pile-and-chain anchor chain mooring scheme is proposed, that is, three piles are placed on the back wave side of the platform, and the platform is moored on the three piles by cables, while the piles and platforms arrange the anti-flip pad between them. At the same 
time, an anchor chain is arranged on the wave side of the platform. The schematic diagram of the mooring system is shown in Fig. 10. The specific parameters of the mooring system are shown in Table 6. The specific details are as follows.

Piles and anti-collision pads: reinforced concrete piles with a diameter of $2 \mathrm{~m}$ and a height of $20 \mathrm{~m}$ are placed at $5 \mathrm{~m}$ from the beginning and the end of the platform, respectively. At the contact position with the platform (waterline, center of the upper platform, $11.35 \mathrm{~m}$ from the platform baseline) A 4.5 $\mathrm{m}$ diameter anti-collision pad is used to prevent the platform from moving to one side of the pile; the cable: $5 \mathrm{~m}$ each at the beginning and the end of the platform, and four $160 \mathrm{~mm}$ diameter polyester cables are fanned at $9.7 \mathrm{~m}$ from the platform baseline ( Connected to the pile at an angle of $60^{\circ}$, each cable has a length of 15 to $20 \mathrm{~m}$. The function of these 24 cables is to prevent the platform from moving in a large amount in the horizontal and vertical directions, thereby playing a positioning role.

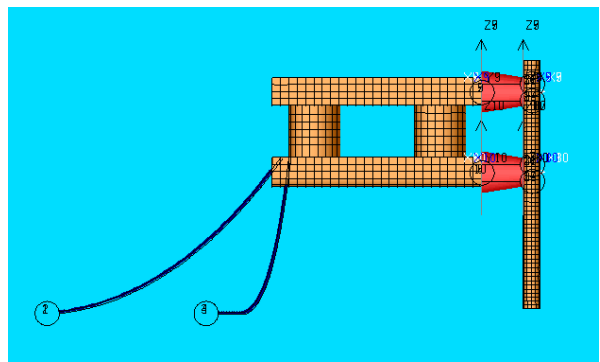

(a)

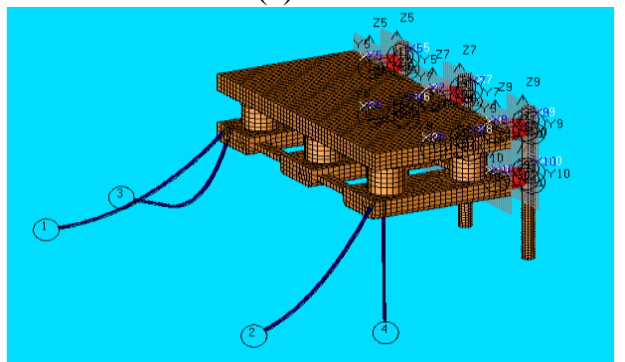

(b)

Fig.10. Pile anchor chain combined mooring system Table 6 Main parameters of mooring lines

\begin{tabular}{|c|c|c|c|c|c|}
\hline & $\begin{array}{c}\text { Leng } \\
\text { th } \\
(\mathrm{m})\end{array}$ & $\begin{array}{c}\text { Diame } \\
\text { ter } \\
(\mathrm{m})\end{array}$ & $\begin{array}{c}\text { Dry } \\
\text { weight } \\
(\mathrm{kg} / \mathrm{m})\end{array}$ & $\begin{array}{c}\text { Stiffness EA } \\
(\mathrm{KN})\end{array}$ & $\begin{array}{c}\text { Breaking } \\
\text { strength(N) }\end{array}$ \\
\hline $\begin{array}{c}\text { Anchor } \\
\text { chain }\end{array}$ & 38 & 0.15 & 391.6 & $1.70 \mathrm{E}+09$ & $1.57 \mathrm{E}+07$ \\
\hline $\begin{array}{c}\text { Polyester } \\
\text { cable }\end{array}$ & 15 & 0.16 & 20.4 & $2.80 \mathrm{E}+04$ & $4.50 \mathrm{E}+06$ \\
\hline $\begin{array}{c}\text { Crash } \\
\text { pad }\end{array}$ & I. - & 4.5 & II. - & $\begin{array}{c}2400 \mathrm{D}-440 \mathrm{D}^{2} \\
+1200 \mathrm{D}^{3}-80 \mathrm{D} \\
\text { (D is the } \\
\text { amount of } \\
\text { deformation, } \\
\text { m) }\end{array}$ & III. - \\
\hline
\end{tabular}

It can be seen from Table 7 and Table 8 that under the new pile-chain anchor chain mooring scheme, the floating shallow water platform has less motion, and its anchor chain is also less stressed than the traditional catenary mooring and Zhang. Tight mooring. From the numerical point of view, the pile-type mooring restricts the wave-frequency response of the platform while limiting the slow-wover motion caused by the second-order force, so the overall motion response of the platform is controlled to a small range.

Table 7 Results of motion response of platform at $90^{\circ}$ wave angle

\begin{tabular}{|c|c|c|c|c|c|}
\hline \multirow{2}{*}{$\begin{array}{c}\text { Freedom } \\
\text { of } \\
\text { movement }\end{array}$} & $\begin{array}{c}\text { Mooring } \\
\text { scheme }\end{array}$ & Maximum & Minimum & Average & Amplitude \\
\hline \multirow{4}{*}{$\begin{array}{c}\text { Sway } \\
(\mathrm{m})\end{array}$} & Catenary & 1.649 & 0.4012 & 0.9137 & 0.6239 \\
\cline { 2 - 6 } & Taut & 1.064 & -0.1058 & 0.0384 & 0.5849 \\
\cline { 2 - 6 } & $\begin{array}{c}\text { Pile anchor } \\
\text { chain } \\
\text { combination }\end{array}$ & 1.677 & 0.856 & 1.332 & 0.4015 \\
\hline \multirow{4}{*}{$\begin{array}{c}\text { Heave } \\
(\mathrm{m})\end{array}$} & Catenary & -0.9326 & -1.971 & -1.497 & 0.5192 \\
\cline { 2 - 6 } & $\begin{array}{c}\text { Pile anchor } \\
\text { chain } \\
\text { combination }\end{array}$ & -1.142 & -2.116 & -1.603 & 0.487 \\
\hline \multirow{4}{*}{$\begin{array}{c}\text { Roll } \\
\left({ }^{\circ}\right)\end{array}$} & Catenary & 3.567 & -0.4470 & 1.701 & 2.007 \\
\cline { 2 - 6 } & Taut & 3.922 & -2.443 & 1.428 & 3.1825 \\
\cline { 2 - 6 } & $\begin{array}{c}\text { Pile anchor } \\
\text { chain } \\
\text { combination }\end{array}$ & 2.482 & -1.278 & 0.9613 & 1.88 \\
\hline
\end{tabular}

Table 8 Statistic results of maximal loads acting for mooring system

\begin{tabular}{|c|c|c|c|c|}
\hline Condition & \multicolumn{4}{|c|}{$90^{\circ}$ wave direction } \\
\hline $\begin{array}{c}H_{s}=1.25 \mathrm{~m} \\
T_{p}=7 \mathrm{~s}, V_{m}=10 \mathrm{~m} / \\
\mathrm{s}\end{array}$ & $\begin{array}{c}\text { Platfrom } \\
(\mathrm{N})\end{array}$ & $\begin{array}{c}\text { Mooring } \\
\text { lines }(\mathrm{N})\end{array}$ & $\begin{array}{c}\text { Crash } \\
\text { pad }(\mathrm{N})\end{array}$ & Pile $(\mathrm{N})$ \\
\cline { 2 - 5 } & $5.8 \mathrm{E} 6$ & $1.46 \mathrm{E} 6$ & $3.434 \mathrm{E} 5$ & $5.75 \mathrm{E} 6$ \\
\hline
\end{tabular}

\section{CONCLUSION}

The floating platform near the island reef has many advantages as a comprehensive support base for marine island reef development, fishery production, environmental tourism, etc. However, the terrain near the island reef is complex and variable, and the water depth is shallow. These are the floating platform mooring system. The design has brought great difficulties. Based on Morison formula, finite depth three-dimensional Green's function and time domain coupled dynamic analysis method, this paper takes a near-island semi-submersible production and living platform as the research object, and analyzes the traditional mooring method and pile-column chain combined mooring mode. The motion of the platform and the dynamic response of the mooring system are the following two main conclusions:

Traditional mooring methods, such as catenary and tension mooring, are commonly used in medium and deep waters, and when they are extended to near-island shallow waters, a series of problems arise, such as platform motion response. If it is too large, the bottoming and negative air gap phenomenon occurs; the platform resonates with the mooring system; the lifting force of the anchor is difficult to eliminate. When optimizing the mooring line length, pre-tension, number of mooring lines and tension angle, the effect is not obvious, and the optimized space is small;

Aiming at the problems existing in the traditional mooring method and the convenience of docking the ship, this paper proposes a new type of pile-chain anchor chain mooring system. From the results of time-domain coupled dynamic analysis, the overall motion response of the platform is small under this mooring system, and there is no bottoming and negative air gap phenomenon, and the force of each part of the mooring system meets the relevant requirements. The mooring problem of the floating platform in the shallow water 
environment near the island reef is solved, which can provide reference for the basin model test of the platform and the design of the floating platform mooring system in the shallow water environment.

\section{REFERENCES}

[1] Kim M H, Tahar A, Kim Y B. Variability of spar motion analysis against various design methodologies/parameters [C]. Proceedings of the Twentieth Offshore Mechanics and Artic Engineering Conference, OMAE, 2001

[2] Kim M H, Koo B J, Mercier R M. Vessel/mooring/riser coupled dynamic analysis of a turret-moored FPSO compared with OTRC experiment $[\mathrm{J}]$ Ocean Engineering, 2005, 32: 1780-1802.

[3] Arcandra, Tahar, Kim M H. Coupled-dynamic analysis of floating structures with polyester mooring lines [J]. Ocean Engineering, 2008, 38(35): 1676-1685.

[4]Wang Lei, Wang Xianfu, Yang Jianmin. Experimental research on second-order wave drift forces on a dynamically positioned ship [J]. Ocean Engineering, 2006, 24(3): 1-5.

[5]Research on hydrodynamic characteristics of a semi-submersible platform and its mooring system [J]. Ocean Engineering, 2010, 28(4):1-8.

[6] Yuan Meng, Fan Ju, Miao Guoping, Zhu Renchuan. Dynamic analysis of a mooring system [J]. Chinese Journal of Hydro- dynamics, 2010, 25(3): 285-291.

[7]Zhou Sulian, Nie Wu, Bai Yong. Investigation on mooring system design of a deepwater semi-submersible platform [J]. Journal of Ship Mechanics, 2010, 14(5): 495-502.

[8] Tong Bo, Yang Jianmin, Li Xin. Coupled dynamic analysis of catenary mooring system for the deepwater semi-submerged platform [J]. China Offshore Platform, 2008, 23(6): 1-7.

[9] Xiao Longfei, Yang Jianmin, Fan Mo, Peng Tao. Research on motions and safety performance of a 160kDWT FPSO in ultra-shallow water [J] Journal of Ship Mechanics, 2006, 10(1): 7-14.

[10] Wu Songren. Coastal Hydrodynamics [M]. Beijing: China Communications Press, 2004

Hui Liu, School of Naval Architecture \& Ocean Engineering, Jiangsu University of Science and Technology, Zhenjiang, Jiangsu, China

Qianqian Jia, School of Naval Architecture \& Ocean Engineering,

Jiangsu University of Science and Technology, Zhenjiang, Jiangsu, China

Xiaofeng Meng, School of Naval Architecture \& Ocean Engineering ,

Jiangsu University of Science and Technology, Zhenjiang, Jiangsu, China

Haoran Liu Chen, School of Naval Architecture \& Ocean Engineering

, Jiangsu University of Science and Technology, Zhenjiang, Jiangsu, China

Shuai Guo, School of Naval Architecture \& Ocean Engineering , Jiangsu

University of Science and Technology, Zhenjiang, Jiangsu, China 